\title{
Validating the breeding value for maternal preweaning gain in beef cattle with measured milk production
}

\author{
M.D. MacNeil ${ }^{\#}$, V.R. Leesburg and T.B. Mott \\ USDA - Agricultural Research Service and Montana Agricultural Experiment Station, Fort Keogh Livestock and Range \\ Research Laboratory, 243 Fort Keogh Road, Miles City, MT 59301 USA
}

\begin{abstract}
The objective of this research was to validate the maternal breeding value for preweaning gain as a predictor of genetic differences in milk production. Phenotypic variation in preweaning gain and in milk production measured by the weigh-suckle-weigh method was partitioned into genetic and non-genetic components. Data were from the Line 1 Hereford cattle maintained by USDA-ARS at Miles City, Montana, USA. Data collected through 2005 included 6835 and 692 observations of preweaning gain and milk production from 2172 and 403 dams and cows since 1935 and 1994, respectively. Data were analyzed using a Gibbs sampler for multiple-trait animal models. Results are reported as mean \pm SD derived from the posterior distribution of parameter estimates. Phenotypic variances of preweaning gain and milk production were $476.3 \mathrm{~kg}^{2}$ and $8.88 \mathrm{~kg}^{2}$, respectively. Heritability estimates for direct and maternal preweaning gain, and milk production were $0.13 \pm 0.03,0.25 \pm 0.04$, and $0.25 \pm 0.06$, respectively. Estimates of genetic and phenotypic correlations between preweaning gain and milk production were $0.80 \pm 0.08$ and $0.37 \pm 0.04$, respectively. The difference between phenotypic and genetic correlations may provide insight into confidence of breeders in genetic evaluation of maternal preweaning gain. Breeding value for maternal preweaning gain was highly predictive of breeding value for milk production. Selection based on the maternal breeding value for preweaning gain may be nearly as effective in changing milk production as direct selection.
\end{abstract}

Keywords: Genetic correlation, growth, heritability

${ }^{\#}$ Corresponding author. E-mail: mike@larrl.ars.usda.gov

\section{Introduction}

Milk production has been positively related to beef production efficiency (e.g., Kress et al., 1969; Freking \& Marshall, 1992; Miller et al., 1999). While milk production has been only assessed directly in experimental settings, partitioning gain from birth to weaning into direct and maternal genetic effects facilitates indirect selection for presumed milk production. However, relatively few studies have validated this assumed relationship (Diaz et al., 1992; Meyer et al., 1994; Miller \& Wilton, 1999). Previous estimates of genetic correlation between milk yield and maternal preweaning gain of 0.80 and 0.76 have been reported (Meyer et al., 1994; Miller \& Wilton, 1999, respectively). Additional estimates of this correlation provide increased confidence in the utility of maternal breeding values for preweaning gain as an indicator of milk production. Thus the objective of this research was to confirm the utility of breeding value for maternal gain from birth to weaning as a predictor of breeding value for milk production.

\section{Materials and Methods}

Cattle used in this research were Line 1 Hereford raised at Fort Keogh Livestock and Range Research Laboratory, Miles City, Montana, USA (Knapp et al., 1951; MacNeil et al., 1992; MacNeil et al., 2000). At this location, annual precipitation averages $34 \mathrm{~cm}$, with $21 \mathrm{~cm}$ occurring during March through July. Average temperatures are $-9^{\circ} \mathrm{C}$ in January and $23^{\circ} \mathrm{C}$ in July. Broken badlands and plains rangelands typical of eastern Montana and the Northern Great Plains Region provided annual support for a cow-calf pair on approximately 14 ha with some supplemental feed during winter. Native vegetation has been predominantly Pascopyrum smithii, Poa secunda, Bouteloua gracilis, Buchloe dactyloides, Hesperostipa comata, Nassella viridula, Carex filifolia, Sarcobatus vermiculatus, Artemisia cana, and Artemisia tridentata spp. wyomingensis. Annual Bromus spp have been increasingly prevalent since the 1980's. 
Calving was in spring, commencing in mid-March and continuing until mid-May of each year. Calves were weighed within $24 \mathrm{~h}$ of parturition. Cow-calf pairs were moved to native rangeland spring pastures a few days after birth. In early June, the cow-calf pairs were moved to breeding pastures of 222 to 549 ha. The first of four estimates of milk production was obtained using a weigh-suckle-weigh procedure within a few days of the movement to breeding pastures. Two subsequent estimates of milk production were similarly obtained from these same cows with the period between the first estimate and weaning divided into three approximately equal intervals. A fourth and final estimate of milk production was obtained at weaning. At each time milk production was recorded, cow-calf pairs were gathered from the breeding pastures to a central handling facility on the day preceding the data collection, and calves were separated from their dams from approximately 1500 to 1800 PM and then reunited and allowed to nurse. Following nursing, the calves were again separated from their dams and remained apart until 0600 the next morning when they were weighed, allowed to nurse until either satiated or milk was no longer available, and quickly reweighed. The difference between weights was assumed to reflect milk consumed by the calf and to measure milk produced by the cow during the preceding $12 \mathrm{~h}$. The four measurements of milk production for a cow during a year were summed to reflect her production during that lactation. Milk production was measured in 1994 to 2005 . Within a year, all calves were weighed and weaned on a single day when their average age was approximately $180 \mathrm{~d}$. Average daily gain from birth to weaning was calculated and multiplied by 180 to obtain preweaning gain for use in the subsequent analysis. Procedures used in this study were reviewed and approved by the Fort Keogh Livestock and Range Research Laboratory Animal Care and Use Committee.

Data analyses were conducted using a multiple-trait Gibbs sampler for animal models (Van Tassell \& Van Vleck, 1996). The linear model for gain from birth to weaning was:

$$
\mathbf{Y}_{1}=\boldsymbol{\mu}+\mathbf{C G}_{1}+\mathbf{b}_{1,1} \mathbf{F}_{\mathbf{x}}+\mathbf{b}_{1,2} \mathbf{F}_{\mathrm{d}}+\mathbf{a}_{1}+\mathbf{u}_{1}+\mathbf{c}_{1}+\mathbf{e}_{1}
$$

wherein, $\mathrm{Y}_{1}=\mathrm{a}$ vector of observations of preweaning gain $(\mathrm{kg})$ linearly preadjusted to a constant age at weaning of $180 \mathrm{~d} ; \mu=$ a constant applicable to all observations; $\mathrm{CG}_{1}=$ a year-sex of calf-age of dam classification effect $(n=491)$ with age of dam recoded as $2,3,4$ and $5+y r ; b_{1,1}=$ the linear regression on inbreeding of calf $\left(F_{x}=0\right.$ to 1.0$) ; b_{1,2}=$ the linear regression on inbreeding of dam $\left(F_{d}=0\right.$ to 1.0$) ; a_{1}=a$ direct genetic effect associated with the calf; $\mathrm{u}_{1}=$ a maternal genetic effect associated with the dam of the calf; $\mathrm{c}_{1}=$ a permanent environmental effect due to the dam; and $\mathrm{e}_{1}=$ temporary environmental effect associated with each phenotype. The linear model for milk production was:

$$
\mathbf{Y}_{2}=\mu+\mathbf{C G}_{2}+\mathbf{b}_{2,1} \mathbf{F}_{\mathbf{d}}+\mathbf{b}_{2,2} \mathbf{D P}+\mathbf{u}_{2}+\mathbf{c}_{2}+\mathbf{e}_{2}
$$

wherein, $\mathrm{Y}_{2}=$ the total of four observations of weigh-suckle-weigh milk production $(\mathrm{kg})$ as described above; $\mu=$ a constant applicable to all observations; $\mathrm{CG}_{2}=$ a year-age of cow classification effect $(\mathrm{n}=72)$ with age of cow recoded as $2,3,4,5,6$ and $7+y r ; b_{2,1}=$ the linear regression on inbreeding of cow $\left(F_{d}=0\right.$ to 1.0$)$; $b_{2,2}$ $=$ the linear regression on day of parturition $(\mathrm{DP}=58$ to 143$) ; \mathrm{u}_{2}=$ a direct genetic effect associated with the cow; $\mathrm{c}_{2}=\mathrm{a}$ permanent environmental effect due to repeated observation of cows over years; and $\mathrm{e}_{2}=$ temporary environmental effect associated with each phenotype.

The multiple-trait model expressed in matrix notation was:

$$
\mathbf{y}=\mathbf{X} \boldsymbol{\beta}+\mathbf{Z u}+\mathbf{Z}_{\mathbf{a}} \mathbf{a}+\mathbf{W c}+\mathbf{e}
$$

where $\mathbf{y}$ is a vector of phenotypes, $\boldsymbol{\beta}$ is the vector of systematic effects, $\mathbf{u}$ is a vector of animal effects associated with the cows (dams), a is a second vector of animal effects associated with the calves and affecting preweaning gain, $\mathbf{c}$ is a vector of permanent environmental effects for repeated records of the phenotypes of each cow, $\mathbf{e}$ is a vector of temporary environmental effects, and $\mathbf{X}, \mathbf{Z}, \mathbf{Z}_{\mathbf{a}}$, and $\mathbf{W}$ are incidence matrices of appropriate dimensions associating the effects with the phenotypes. Inverted Wishart distributions, with shape parameters equal to the minimums required for proper prior distributions were assumed for the (co)variances of $\mathbf{u}, \mathbf{a}, \mathbf{c}$, and $\mathbf{e}$, as shown below: 


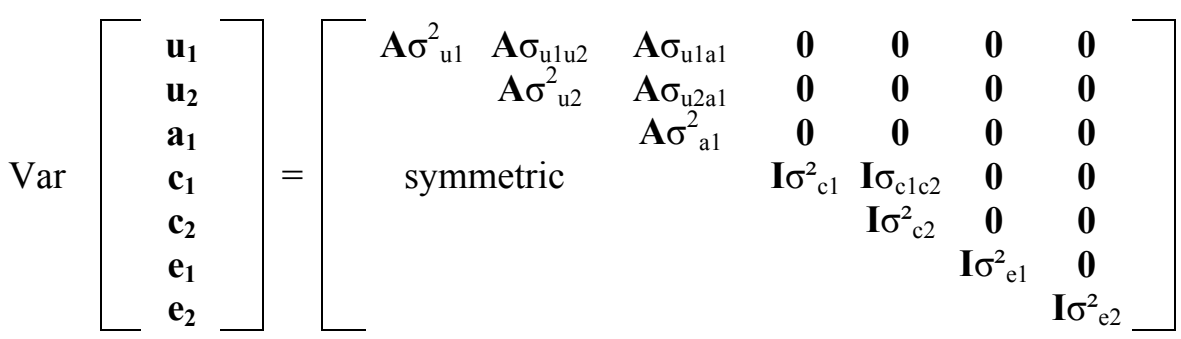

where, $\mathbf{A}$ is the additive relationship matrix among animals in the pedigree file $(n=8507)$. Note, the temporary environmental covariance of milk production with preweaning gain is zero, because these phenotypes are measured on different animals. An initial analysis was conducted to obtain Gibbs samples from a chain of 55,000 rounds, saving every $50^{\text {th }}$ round, and discarding the first 5,000 rounds as burn-in. The Gibbsit program of Raftery \& Lewis (1996) was used to evaluate the chain length, length of burn-in period, and thinning interval needed to obtain stationary chains of independent samples required for the cumulative distribution function of the 0.025 quantile to be estimated within \pm 0.0125 with a probability of 0.95 for each (co)variance component. Based on the results of this initial analysis a final analysis was conducted using a burn-in of 10,000 rounds, 200,000 rounds of post-burn-in Gibbs sampling, and a thinning interval of 200 rounds. In summarizing the Gibbs samples, results are reported as mean $\pm \mathrm{SD}$ of posterior samples.

\section{Results and Discussion}

There were 6,835 observations of preweaning gain of calves from 2172 dams and 252 sires. Due to logistical constraints, it was only feasible to collect milk production data from samples of approximately 57 cows each year. In total, milk production of 403 cows was measured and there was an average of 1.7 observations per cow. These cows were sired by 91 bulls. Unadjusted mean values for $180-\mathrm{d}$ preweaning gain and total weigh-suckle-weigh milk production were $148.6 \mathrm{~kg}$ and $9.5 \mathrm{~kg}$, respectively. Corresponding phenotypic variances derived from the posterior distribution were $476.2 \mathrm{~kg}^{2}$ and $8.86 \mathrm{~kg}^{2}$. Posterior means for heritability of direct and maternal effects on preweaning and of weigh-suckle-weigh milk production were $0.13 \pm 0.03,0.25 \pm 0.04$, and $0.25 \pm 0.06$, respectively. Average estimates of direct and maternal heritability for preweaning gain from Koots et al. (1994a) are at the $34^{\text {th }}$ and $62^{\text {nd }}$ percentiles of the respective posterior distributions in this study. Similarly, the average estimates for preweaning gain from this study are within 1.0 observed SD of the corresponding mean of estimates summarized by Koots et al. (1994a).

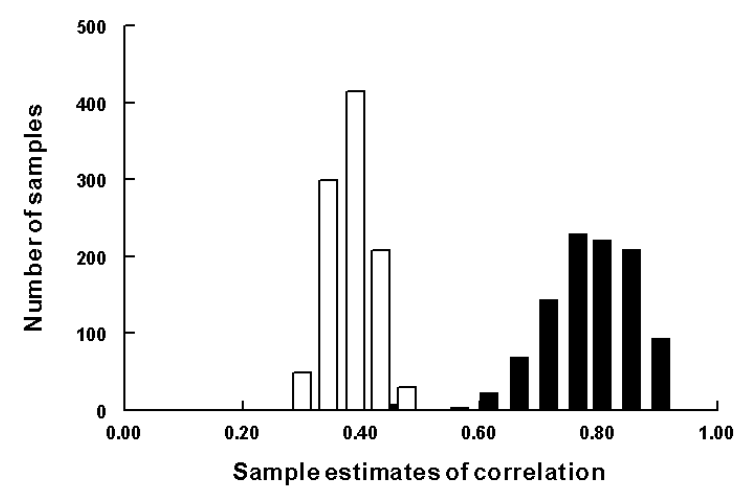

Figure 1 Marginal posterior distributions of Gibbs sample estimates of genetic (solid bars) and phenotypic correlations (open bars) between maternal preweaning gain and weigh-suckle-weigh milk production

The posterior distributions of samples of genetic and phenotypic correlations between maternal preweaning gain and milk production are shown in Figure 1. Validity of using the maternal breeding value for preweaning gain as a predictor of breeding value for milk production rests on the premise that their genetic correlation is not different from unity. Robertson (1959) posed the question of how much less than 1.0 this correlation must be before it has biological importance and suggested the figure of 0.8 with a 
standard error of 0.2 ; i.e. a lower threshold of 0.6 . In these data $98.8 \%$ of the samples from the posterior distribution exceeded this threshold. The shift of the phenotypic correlation toward zero relative to the genetic correlation may provide insight into the confidence breeders have in genetic evaluation of maternal preweaning gain as indicative of genetic potential for milk production from observation of phenotypes.

The average estimate of the genetic correlation between maternal effects on preweaning gain and milk production was $0.80 \pm 0.08$. This estimate is consistent with similar estimates of 0.80 from Meyer et al. (1994) for Hereford and Wokalups and 0.76 from Miller \& Wilton (1999) for Hereford and multi-breed rotational cross cattle. The estimate of Meyer et al. (1994) was calculated from single observations of milk production per lactation obtained by the weigh-suckle-weigh method near the time of peak lactation. Whereas, Miller \& Wilton (1999) used two to four records from machine milking following oxytocin injection after a 6-hr calf removal to estimate 200-d milk yield. Differences among studies in protocol for measuring milk production make comparisons of levels of milk production suspect. However, the consistency of estimates of the genetic correlation between milk production and maternal preweaning gain across these independent studies seems strong evidence to consider breeding value for maternal gain an accurate indicator of breeding value for milk production. Based on the present data, selection to change milk production using the indicator trait maternal gain from birth to weaning would be, on average, $82 \pm 14 \%$ as effective as mass selection. In $11 \pm 31 \%$ of samples from the posterior distribution, selection based on maternal breeding value for the indicator trait preweaning gain would be as or more efficient in altering milk production than direct selection.

\section{Conclusions}

Data from three independent studies using different measures of individual milk production support the conclusion that breeding value for maternal gain from birth to weaning is a useful predictor of breeding value for milk production. Breeders can base selection on the breeding value for maternal preweaning gain and be confident in changing milk production nearly as effectively as if direct selection were practiced.

\section{Acknowledgement}

This research was conducted under a cooperative agreement between USDA-ARS and the Montana Agricultural Experiment Station (MAES). Mention of a proprietary product does not constitute a guarantee or warranty of the product by USDA, MAES or the authors and does not imply its approval to the exclusion of other products that may also be suitable. USDA-ARS, Northern Plains Area is an equal opportunity and affirmative action employer. All agency services are available without discrimination.

\section{References}

Diaz, C., Notter, D.R. \& Beal, W.E., 1992. Relationship between milk expected progeny differences of Polled Hereford sires and actual milk production of their crossbred daughters. J. Anim. Sci. 70, 396402.

Freking, B.A. \& Marshall, D.M., 1992. Interrelationships of heifer milk production and other biological traits with production efficiency to weaning. J. Anim. Sci. 70, 646-655.

Knapp, B., Church, R.C. \& Flower, A.E., 1951. Genetic history of Line 1 Hereford cattle at the United States Range Livestock Experiment Station. Miles City, Montana. Bull. 479. Montana State College, Agric. Exp. Sta., Bozeman.

Koots, K.R., Gibson, J.P., Smith, C. \& Wilton, J.W., 1994. Analyses of published genetic parameter estimates for beef production traits. 2. Heritability. Anim. Breed. Abstr. 62, 309-338.

Kress, D.D., Hauser, E.R. \& Chapman, A.B., 1969. Efficiency of production and cow size in beef cattle. J. Anim. Sci. 29, 373-383.

MacNeil, M.D., Urick, J.J. \& Decoudu, G., 2000. Characteristics of Line 1 Hereford females resulting from selection by independent culling levels for below-average birth weight and high yearling weight or by mass selection for high yearling weight. J. Anim. Sci. 78, 2292-2298.

MacNeil, M.D., Urick, J.J., Newman, S. \& Knapp, B.W., 1992. Selection for postweaning growth in inbred Hereford cattle: The Fort Keogh, Montana Line 1 example. J. Anim. Sci. 70, 723-733. 
Meyer K., Carrick, M.J. \& Donnelly, B.J.P., 1994. Genetic parameters for milk production of Australian beef cows and weaning weight of their calves. J. Anim. Sci. 72, 1155-1165.

Miller, S.P. \& Wilton, J.W., 1999. Genetic relationships among direct and maternal components of milk yield and maternal weaning gain in a multibreed beef herd. J. Anim. Sci. 77, 1155-1161.

Miller, S.P., Wilton, J.W. \& Pfeiffer, W.C., 1999. Effects of milk yield on biological efficiency and profit of beef production from birth to slaughter. J. Anim. Sci. 77, 344-352.

Raftery, A.E. \& Lewis, S.M., 1996. Implementing MCMC. Pages 115-130 in Markov Chain Monte Carlo in Practice. Gilks, W. R., Spiegelhalter, D. J. \& Richardson, S., ed. Chapman and Hall, London, U.K.

Robertson, A., 1959. The sampling variance of the genetic correlation coefficient. Biometrics 15, 469-485.

Van Tassell, C.P. \& Van Vleck, L.D., 1996. Multiple trait Gibbs sampler for animal models: Flexible programs for Bayesian and Likelihood-based (co)variance component inference. J. Anim. Sci. 74, 2586-2597. 